\title{
Design and development of Bi directional power meter using microcontroller
}

\author{
Tasnim Ikra Rahman', Anika Fariha Rashid², Md. Habibur Rahman ${ }^{3}$ \\ ${ }^{1}$ Department of Electronics and Telecommunication Engineering, Daffodil International University, Bangladesh \\ ${ }^{2}$ Institute of Energy, Dhaka University, Bangladesh \\ ${ }^{3}$ Department of Electrical and Electronic Engineering, Dhaka University, Bangladesh
}

\begin{tabular}{l}
\hline Article Info \\
\hline Article history: \\
Received Jan 10, 2019 \\
Revised May 1, 2019 \\
Accepted Jul 1, 2019 \\
\hline
\end{tabular}

\section{Keywords:}

Bi Directional

Grid

Load

Power

\begin{abstract}
The significance of power or energy measurement has been very acute in recent times with the increase of Grid-Tied Solar PV system that needs NetMetering. Power can be flown in both directions, from grid to load or from load (PV- Panel) to grid line. If power flow from both side is not calculated and surplus power which is not being used at the time instant is not stored, accurate billing is not possible. That is why a bidirectional power meter is required which can measure both the positive and negative power at any instant. The aim of this paper is to develop a bidirectional power meter using microcontroller. The work of this paper constitutes a microcontroller, a current sensor, bulbs as load and a display. The rms values of voltage and current is determined and showed in the display. Then the calibration is done inside the developed program. After that the power is calculated and showed in the display. Then the direction of the power is determined depending on the direction (whether positive or negative) of the power which is also dependent on the phase difference between the voltage and current. If there is no phase difference between the voltage and current, then the power is positive and leaving from the grid. If there is 180 degree phase difference between the voltage and current, then the power is negative and entering to the grid. The direction of the power flow is very important for efficiently of the proposed meter. For some defined load the accuracy of the developed meter is calculated as $94 \%$.
\end{abstract}

Copyright $@ 2020$ Institute of Advanced Engineering and Science. All rights reserved.

\section{Corresponding Author:}

Tasnim Ikra Rahman,

Department of Electronics and Telecommunication Engineering,

Daffodil International University, Dhaka 1207, Bangladesh.

Email: ikrarahmantasnim54@gmail.com

\section{INTRODUCTION}

Accuracy of power measurement is a vital requirement of energy sector now-a-days for Grid-Tied PV systems. According to Energy Efficiency and Conservation Rule, Government has committed EE\&C implementation within 2030 [1-6]. The voltage or current producing in a power producing device or solar panel can be measured easily and so the power. But in case of Grid-Tied Solar PV system power may come from grid to the system at the time of low radiation. This power coming from grid is known as positive power. And power producing by generator or solar panel that goes to the grid is known as negative or outgoing power. The incoming and outgoing power have to be measured using a bidirectional power meter. Here a bidirectional power meter has been developed using Arduino nano board as microcontroller. The program code has been developed using Arduino software. At present time, proper measurement of voltage and current is vital for reducing the system loss of electricity. If power coming from grid and going out from the generated device cannot be measured and stored, the net bill cannot be calculated. For this purpose a low cost meter has been designed using locally available devices. The direction of power flow can also be determined using this meter. 
Root Mean Square (rms) values of voltage and currents can be displayed here by developing a code in IDE (Integrated Discrete Environment) and integrating the power the KWh can be calculated [7-12].

\section{METHODOLOGY}

The complete hardware of the bidirectional meter consists of four units. The block diagram of the complete system is shown in the Figure 1.

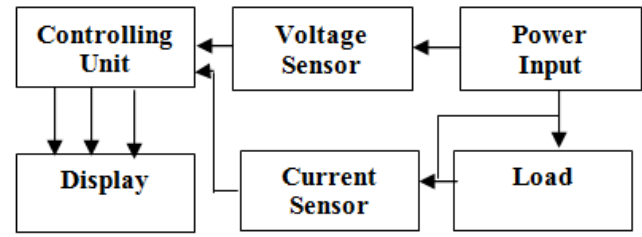

Figure 1. Block diagram of the developed system

\subsection{Controlling Unit}

As the system will be driven by the software, the control unit has been developed using a microcontroller based board. Although this unit could have been developed using discrete microcontroller, (for Eg. PIC, ATmega etc) for the simplicity of design, here an arduino nano board has been used.

Two analog signals have to be measured here for the design purpose and Arduino nano has more than one analog input channels with sufficient number of input output pins to interface. The display unit has been interfaced to the input output pins of the Arduino nano board so that it has been wise in the contest of system cost.

\subsection{Voltage Conditioning Circuit}

Although the microcontroller or Arduino board can measure voltage, $220 \mathrm{~V}$ line voltage is very high to be directly applied to the microcontroller. Hence a Voltage Conditioning Circuit has been developed using a step down transformer. The transformer converts the $220 \mathrm{~V}$ line voltage to $12 \mathrm{~V}[13,14]$. As $12 \mathrm{~V}$ is yet greater than the Arduino input capacity (5V), a voltage divider circuit has been used (1:10). The output of the Voltage Conditioning Circuit is AC so that it has both positive and negative half cycle. But the Arduino cannot read negative voltage. To shift this negative voltage to a suitable level, a $3.7 \mathrm{~V} \mathrm{DC}$ voltage source has been used in series. The output of the Voltage Conditioning Circuit has directly been connected to analog input A1 of Arduino nano board. The Experimental or hardware setup of the system of metering is shown in Figure 2.

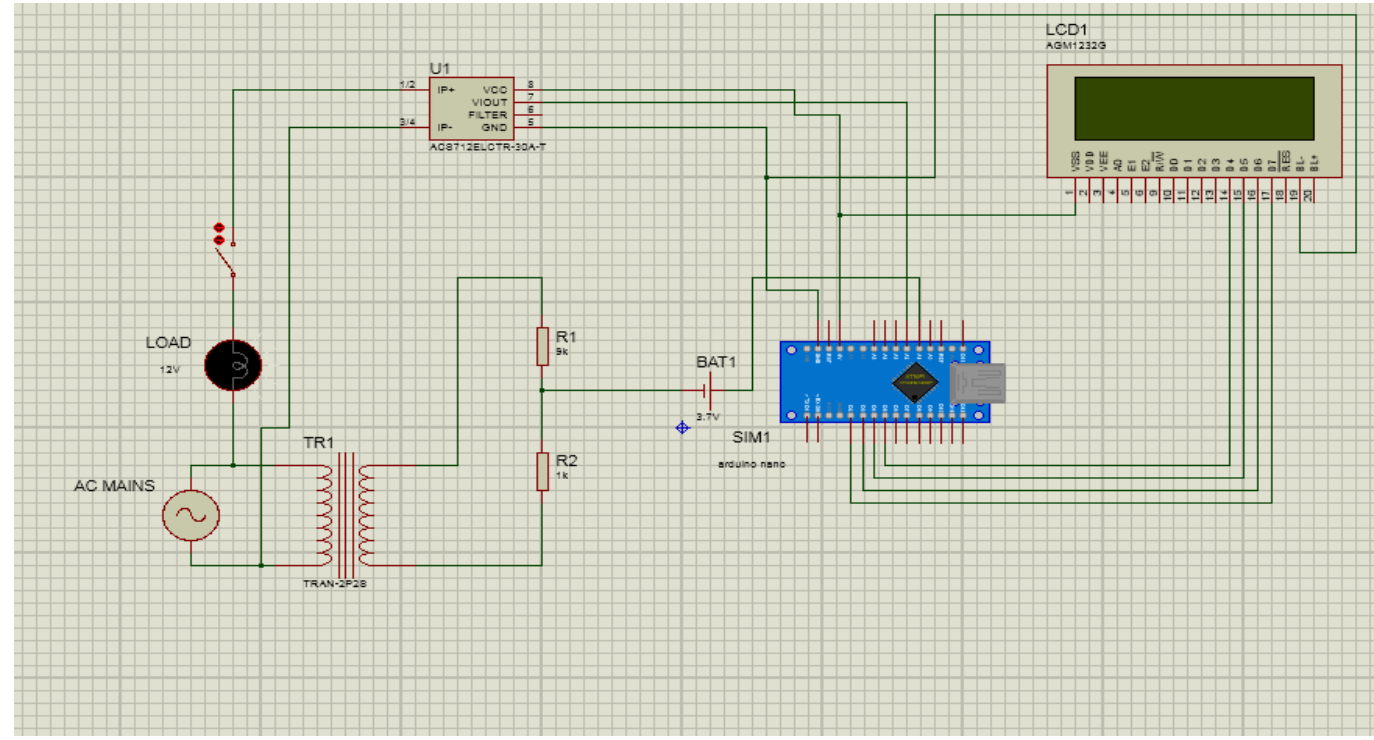

Figure 2. Schematic diagram of the complete system 


\subsection{Current Sensor}

Different types of current sensors can be used for designing the system. Here a hall effect current sensor has been used (ACS 712) which is a bidirectional current sensor. The current capacity of this sensor ranges between -30 Amp to $30 \mathrm{Amp}$. In this research, $30 \mathrm{Amp}$ current sensor has been selected to increase the capacity of the developed meter. Hence, the capacity of the developed meter will be:

$$
30 \mathrm{~A} \times 220 \mathrm{~V}=6600 \mathrm{Watt}=6.6 \mathrm{KW}
$$

When no current flows through the current sensor, output voltage is $2.5 \mathrm{~V}$. For the positive half cycle of the current, output goes from $2.5 \mathrm{~V}$ to $5 \mathrm{~V}$. For the negative half cycle of the current, output goes from 2.5 $\mathrm{V}$ to $0 \mathrm{~V}$. Since, the output voltage range of the current sensor is already within the range of the Arduino, no conditioning circuit is required. The output of the current sensor has directly been connected to analog input pin A2 of Arduino nano.

The performance characteristics of the current sensor is shown in Figure 3.

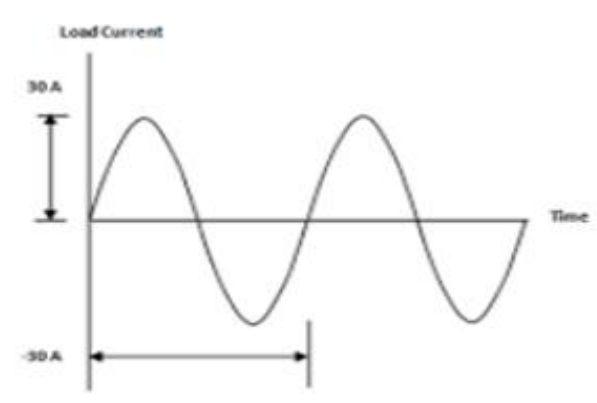

(b) Input to current sensor

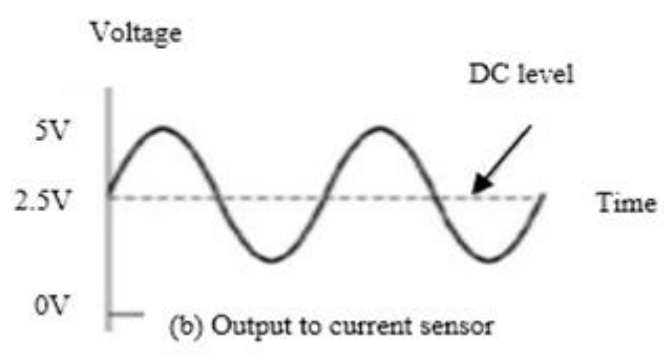

Figure 3. Input and output of current sensor

\subsection{LCD Display}

LCD display can be used in two configurations. For a 8 bit display data will be sent at a time. Here, 4 bit display has been used as Arduino nano has less number of I/O pins. For a 4 bit display system, data has to be sent twice. All the units have been interconnected to make the complete system.

\section{RESULTS}

The whole system is controlled by a program. The program has been developed using Arduino IDE (Integrated Development Environment). The program has mainly two algorithms.

a) One is to determine the rms value from the sinusoidal current and voltage.

b) Another one is to determine the direction of power flow.

\subsection{RMS Value Calculation}

For calculating the incoming and outgoing power at first the rms value of voltage and current has to be determined. Voltage and Current of the system following sinusoidal shaped wave may have phase shifts. The flowchart for calculating voltage and current is given below in Figure 4.

As Arduino speed is limited, it is difficult to switch between voltage and current again and again. If voltage and current is switched repeatedly data will be lost during this period of time. That is why samples of voltage and current are taken at the same time for measuring rms value of voltage and current. Data will not be changed for this short period of time. After getting the value of voltage and current power will be calculated using this formula $\mathrm{P}=\mathrm{V} \times \mathrm{I}$ (for resistive load). Simultaneous value of voltage and current has been determined for calculating the positive and negative power.

When the calibration mode is zero, the measured value of voltage and current from the line can be calculated by using Multimeter and Clampmeter respectively. This value of voltage and current have to be calibrated with scaling factor. While running the mode 1 of Arduino code, Unscaled voltage and Current will be appeared at the LCD display. These values of unscaled voltage and current have to be stored for further calculation of calibration. 


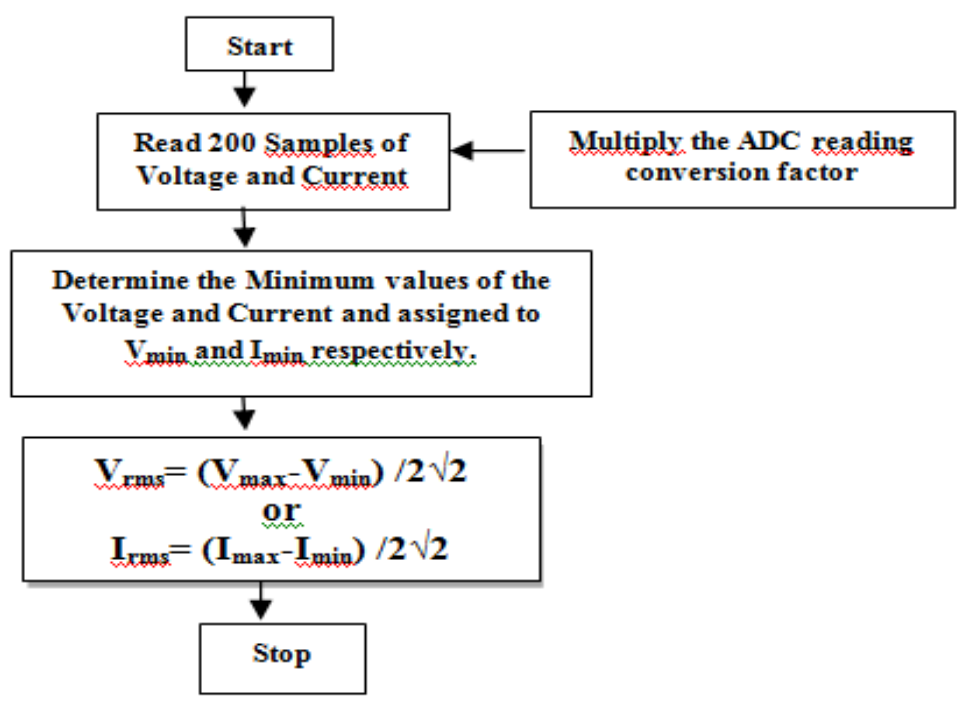

Figure 4. Flow chart for measuring rms voltage and current For Voltage:

The calibrated value can be determined for the following formula used in Arduino code:

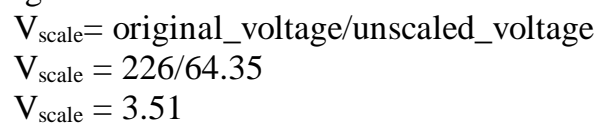

Measured voltage from line by multimeter $=226.7 \mathrm{~V}$

Unscaled_voltage $=64.35 \mathrm{~V}$

Measured current by clapmmeter $=0.27$

Here unscaled voltage is the line voltage but it is needed to be calibrated and then the calibrated voltage will become scaled voltage. The line voltage is too high to run the microcontroller (Arduino nano). For running an Arduino nano very little dc voltage (like 2 to 3 volts) is needed. The line voltage is 220 volts and it is made 12 volts by using a 220 to 12 volts step down transformer. Then by a voltage controlling circuit and with the help of a battery Arduino input is given. The output of the Arduino nano is in terms of very low voltage but 220 volts were given so the un scaled voltage is calibrated with the calibration factor and then it is called the scaled voltage.

For Current:

$$
\begin{aligned}
& \mathrm{I}_{\text {scale }}=\text { original_current/unscaled_current } \\
& \mathrm{I}_{\text {scale }}=0.27 / 30.1 \\
& \mathrm{I}_{\text {scale }}=0.0089
\end{aligned}
$$

Measured current by clapmmeter $=0.27 \mathrm{~A}$

$$
\text { Unscaled_current }=30.1 \mathrm{~A}
$$

Here unscaled current is the line current but it is needed to be calibrated and then the calibrated voltage will become scaled current. The line current is too high to run the microcontroller (Arduino nano). For running an Arduino nano very little dc current is needed. The line voltage is 220 volts and it is made 12 volts by using a 220 to 12 volts step down transformer. Then by a current sensor the grid current is measured and con verted into a voltage. With the help of a battery Arduino input is given. The output of the Arduino nano is in terms of very low but the grid current was very high so the calibration of both voltage and current is needed.

\subsection{Experimental findings}

All the sections are constructed in a bread board and complete setup in shown in the Figure 5. 


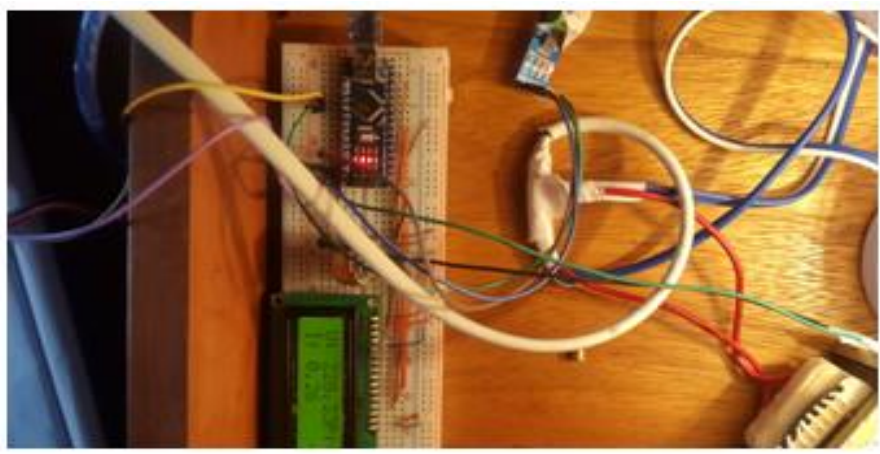

Figure 5. Complete hardware setup

\subsubsection{Positive Power}

The positive power that is absorbed by the load can be determined by the difference between the phases of voltage and current coming from the grid to the load. If there is no phase difference between the voltage and current, then the power is positive [15-20].

In this project, a program in Arduino software is developed where the phase difference can be detected and then it is run with the hardware setup. Then the result is shown in the display as +ve. Now the positive power means that this power is coming from the grid line. Data table for positive power shown in Table 1.

Table 1. Data Table for Positive Power

\begin{tabular}{|c|c|c|c|c|c|c|c|c|c|}
\hline $\begin{array}{c}\text { Value of } \\
\text { loads }\end{array}$ & & $25 \mathrm{w}$ & & & $40 \mathrm{~W}$ & & & $60 \mathrm{~W}$ & \\
\hline $\begin{array}{c}\text { and } \\
\text { parameters } \\
\text { measured }\end{array}$ & $\begin{array}{l}\text { Measured } \\
\text { by Meter }\end{array}$ & $\begin{array}{c}\text { Measured } \\
\text { Value }\end{array}$ & $\begin{array}{l}\text { Percentag } \\
\text { e of Error }\end{array}$ & $\begin{array}{l}\text { Measured } \\
\text { by Meter }\end{array}$ & $\begin{array}{c}\text { Measured } \\
\text { Value }\end{array}$ & $\begin{array}{l}\text { Percentage } \\
\text { of Error }\end{array}$ & $\begin{array}{l}\text { Measured } \\
\text { by Meter }\end{array}$ & $\begin{array}{c}\text { Measured } \\
\text { Value }\end{array}$ & $\begin{array}{c}\text { Percentage } \\
\text { of Error }\end{array}$ \\
\hline $\mathrm{V}_{\mathrm{rms}}$ & 210 & 200 & 3.75 & 230 & 223 & 8.42 & 220 & 215 & 4.87 \\
\hline $\mathrm{I}_{\mathrm{rms}}$ & 0.11 & 0.12 & & 0.18 & 0.17 & & 0.28 & 0.27 & \\
\hline $\begin{array}{c}\text { Power } \\
(+\mathrm{ve})\end{array}$ & 23.1 & 24 & & 41.4 & 37.91 & & 61.6 & 58.6 & \\
\hline
\end{tabular}

\subsubsection{Negative Power}

The negative power can be determined by the difference between the phases of voltage and current coming from the grid. If there is a 180 degree phase difference between the voltage and current, then the power is negative which can be also measured using this proposed meter. Data table for negative power shown in Table 2 and the test setup shown in Figure 6.

Table 2. Data Table for Negative Power

\begin{tabular}{|c|c|c|c|c|c|c|c|c|c|}
\hline $\begin{array}{c}\text { Value of } \\
\text { loads }\end{array}$ & & $25 \mathrm{w}$ & & & $40 \mathrm{~W}$ & & & $60 \mathrm{~W}$ & \\
\hline $\begin{array}{c}\text { and } \\
\text { parameters } \\
\text { measured }\end{array}$ & $\begin{array}{l}\text { Measured } \\
\text { by Meter }\end{array}$ & $\begin{array}{l}\text { Measured } \\
\text { Value }\end{array}$ & $\begin{array}{c}\text { Percentage } \\
\text { of Error }\end{array}$ & $\begin{array}{l}\text { Measured } \\
\text { by Meter }\end{array}$ & $\begin{array}{l}\text { Measure } \\
\text { d Value }\end{array}$ & $\begin{array}{c}\text { Percentage } \\
\text { of Error }\end{array}$ & $\begin{array}{l}\text { Measured } \\
\text { by Meter }\end{array}$ & $\begin{array}{l}\text { Measured } \\
\text { Value }\end{array}$ & $\begin{array}{l}\text { Percentage } \\
\text { of Error }\end{array}$ \\
\hline $\mathrm{V}_{\mathrm{rms}}$ & 231.36 & 234.74 & & 240.36 & 238.59 & & 251.23 & 246.74 & \\
\hline $\mathrm{I}_{\mathrm{rms}}$ & 0.12 & 0.11 & 7.06 & 0.17 & 0.16 & 6.58 & 0.25 & 0.24 & 5.71 \\
\hline $\begin{array}{c}\text { Power } \\
\text { (-ve) }\end{array}$ & 27.76 & 25.8 & & 40.86 & 38.17 & & 62.81 & 59.22 & \\
\hline
\end{tabular}




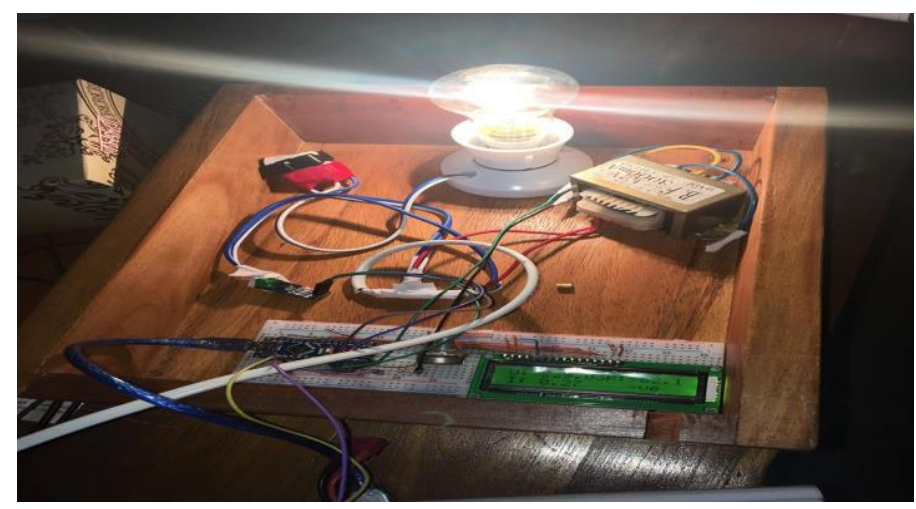

Figure 6. Test setup photography

The power that is displayed in usual case is considered as positive power as a bulb is used as load which is a power consumption device [21-26]. If any power producing device like generator is connected then negative power can be produced.

\section{CONCLUSION}

Total System Cost summary is calculated and the proposed system has been proved as cost effective. All the components used in this system are affordable. For displaying the negative power without changing the current direction, a generator can be connected at the end for further improvement of the system. In this paper, power factor calculation is not added which can be developed later.

\section{REFERENCES}

[1] Sustainable and Renewable Energy Development Authority (SREDA) and Power Division Ministry of Power, "Energy and Mineral Resources Government of the People's Republic of Bangladesh," Energy Efficiency and Conservation Master Plan up to 2030, 2015.

[2] Md. Habibur Rahman, Nasif Shams, Gour Chand Mazumder and Saiful Huque, 2018. "A Data Acquisition System for Solar PV Module with Variable Load."

[3] A. M. Fahmy, M. S. Hamad, and M. A. Mahmond Sayed, "Tarek A. Madbouly.Smart Bidirectional Energy Meter For A Grid-Interfaced Electric Vehicle Charger," European Journal of Engineering and Technology, vol. 5, no.1, 2017.

[4] Bi-Directional Metering, website: https://www.firstenergycorp.com/content/dam/feconnect/files/retail/Net-MeteringPrimer.pdf, 2018.

[5] M. Davoodabadi Farahani, and H. Aghajani, "Identification of Potential Groundwater Zones Using RS and GIS, UCT Journal of Research in Science," Engineering and Technology, Issue. 4, pp. 04-06, 2013.

[6] Ahadiat, M. R., Azmi, P., \& Haghbin, A. (2015). "The Mitigation of the Effect of Impulsive Noise in OFDM-PLC Systems." UCT Journal of Research in Science, Engineering and Technology, 3(1), 18-25.

[7] S.Monisha, M.Monisha, P. Deepa, R. Sathya, K.Gunasekaran (2019). "An android application for exhibiting Statistical chronicle information.” International Journal of Communication and Computer Technologies, 7 (1), 7-9.

[8] Trupa, K., Gandhi, S., Nidhi, P., Dhruvisha, C., \& Kadiya, M. J. (2019). "Formulation and Evaluation Nasal in Situ Gel Of Rizatriptan”. International Journal of Pharmacy Research \& Technology, 9 (2), 49-64.

[9] Tereso, A., Ribeiro, P., \& Cardoso, M. (2018). “An Automated Framework for the Integration between EVM and Risk Management.” Journal of Information Systems Engineering \& Management, 3(1), 03.

[10] Sakthive, V., Kesaven, P. V., Martin William, J., \& Madan Kumar, S. K. (2019). "Integrated platform and response system for healthcare using Alexa." International Journal of Communication and Computer Technologies, 7 (1), 14$22,2016$.

[11] Montazeri-Gh M, Mahmoodi-K M. "Optimized predictive energy management of plug-in hybrid electric vehicle based on traffic condition”. Journal of cleaner production. 15;139: 935-48, 2016.

[12] Hildayanti, S., \&Alie, J. "Factors Influenced Paddy Farmers To Use Or Not Use Organic Fertilizers In South Sumatera, Indonesia." Humanities \& Social Sciences Reviews, 4(1), 53-58, 2016

[13] Sadeghnejad S., Sadighi M. and Hatamizadeh, A., “Contact Force Estimation of Viscoelastic Sandwich Structures under Low Velocity Impact, Using Artificial Neural Network (ANN)," The 3rd International Conference on Composites: Characterization, Fabrication and Application (CCFA-3), December 18-19, 2012, Tehran, Iran 
[14] Rizwan, M., Ahmed, M., \& Gul, S. "Ideology and Politics of Jamiat Ulema-i-Islam" (1947-1973). Global Social Sciences Review, III (I), 45-56, 2018.

[15] Rauf, S., Kalim, I., \& Mubeen, M. "Impact of Electronic Media on Pakistan's Security". Global Social Sciences Review, III (I), 434-446, 2018.

[16] Pourasad, Y., Mahmoodi-k, M. and Oveisi, M. "Design of an optimal active stabilizer mechanism for enhancing vehicle rolling resistance”. Journal of Central South University, 23(5), pp.1142-1151, 2016.

[17] Shah, N., Aajiz, N. M., \& Idris, M. "Failure in the English Subject in Government High Schools for Boys in District Mardan, Khyber Pakhtunkhwa Pakistan.” Global Social Sciences Review, III (II), 146-158. 2018.

[18] Saleem, M., Khan, F. A., \& Zaman, A. "Wh-Movement Pattern in the Spoken Discourse of Teachers A Syntactic Analysis." Global Social Sciences Review, III (II), 400-420, 2018.

[19] Swetapadma Panigrahi, Amarnath Thakur, Modeling and simulation of three phases cascaded H-bridge grid-tied PV inverter, Bulletin of Electrical Engineering and Informatics, vol 8, no. 1, pp 1-9, 2019.

[20] Mukrimah Nawir, Amiza Amir, Naimah Yaakob, Ong Bi Lynn, "Effective and efficient network anomaly detection system using machine learning algorithm," Bulletin of Electrical Engineering and Informatics, vol 8, no. 1, pp 46-51, 2019.

[21] Siti Rohani Tajuddin, S. N. Azemi, P. J. Soh, C.B.M. Rashidi, A Abdullah Al-Hadi, "Analysis and design of directive antenna using frequency selective surface superstrate," Indonesian Journal of Electrical Engineering and Computer Science (IJEECS), vol. 14, no. 2, 529-536, 2019.

[22] N. Abdul Malik, Z. Wahid, A. F. Zulkipili, S. Noorjannah Ibrahim, T. S. Gunawan, Sheroz Khan, "Investigation of lower limb's muscles activity during performance of salat between two age groups," Indonesian Journal of Electrical Engineering and Computer Science (IJEECS),, vol. 14, no. 2, 608-617, 2019.

[23] Madanipour V., Montazeri-Gh M., and Mahmoodi-k M., "Multi-objective component sizing of plug-in hybrid electric vehicle for optimal energy management." Clean Technologies and Environmental Policy 18, no. 4 1189-1202, 2016.

[24] M.S. M. Gismalla, M.F. L. Abdullah, "Performance evaluation of optical attocells configuration in an indoor visible light communication," Indonesian Journal of Electrical Engineering and Computer Science (IJEECS),, vol. 14, no. 2, 668-676, 2019.

[25] Hualei Wang, Hanjing Zhang, Chengqing Song, Chao Xu, "The Impact of HVDC Links on Transmission System Collapse," Indonesian Journal of Electrical Engineering and Computer Science (IJEECS),, vol. 16, no. 1, 21-31, 2018.

[26] Garima Sinha, Pankaj Kumar Goswami, Sudhir Kumar Sharma, "A Comparative Strategy Using PI \& Fuzzy Controller for Optimization of Power Quality Control," Indonesian Journal of Electrical Engineering and Informatics, vol. 16, no. 1, 118-124, 2018. 